\title{
Site-specific methylation of the CMV promoter alters transcriptional factor-transgene interactions and demethylation leads to enhanced specific productivity of a recombinant monoclonal antibody in $\mathrm{CHO}$ cultures
}

\author{
Hussain Dahodwala ${ }^{1}$, Sophia Amenya ${ }^{2}$, Sarah Nicoletti ${ }^{3}$, Matthew Henry ${ }^{4}$, Diane \\ Lees-Murdock $^{2}$, and Susan T. Sharfstein ${ }^{3}$ \\ ${ }^{1}$ NIIMBL \\ ${ }^{2}$ Ulster University - Coleraine Campus \\ ${ }^{3}$ SUNY Polytechnic Institute \\ ${ }^{4}$ The University of Queensland - Saint Lucia Campus
}

August 23, 2021

\begin{abstract}
Chinese hamster ovary (CHO) cells are the industry standard cell line for high yield expression of biopharmaceuticals. However, leveraging the influencers of specific productivity to expedite generation of high productivity clones remains a challenge. One factor impacting specific productivity is the strong, constitutive activity of the CMV promoter used in most vectors for transgene applications. In this study, we sought to understand the influence of DNA methylation along the CMV promoter in driving transcription in higher vs lower productivity cell lines. Bisulfite pyrosequencing was used to characterize the CMV methylation pattern in parental (lower productivity) and DHFR-amplified (higher productivity) monoclonal antibody-expressing cell lines. In-silico analysis of promoter sequence revealed a large CpG island covering the transcription factor binding sites for CREB1 and NF $\varkappa$ B. Variable methylation of specific CpG sites appears correlated with transcription factor binding. Treatment of the cells with 5'-azacytidine, a known DNA hypomethylation agent, led to methylation reduction in the CMV promoter, particularly upstream of the NF $\varkappa B$ binding consensus region. This induced DNA hypomethylation correlated with cell line-specific increases in RNA expression and specific productivity. These encouraging findings suggest that site-specific methylation along the CMV promoter plays an underutilized, and important role in improving transgene transcription using the CMV promoter and debottlenecking the production capacity of $\mathrm{CHO}$ cell lines.
\end{abstract}

\section{Hosted file}

aza_epigenetics paper final no figures.docx available at https://authorea.com/users/431450/ articles/534952-site-specific-methylation-of-the-cmv-promoter-alters-transcriptionalfactor-transgene-interactions-and-demethylation-leads-to-enhanced-specific-productivityof-a-recombinant-monoclonal-antibody-in-cho-cultures 

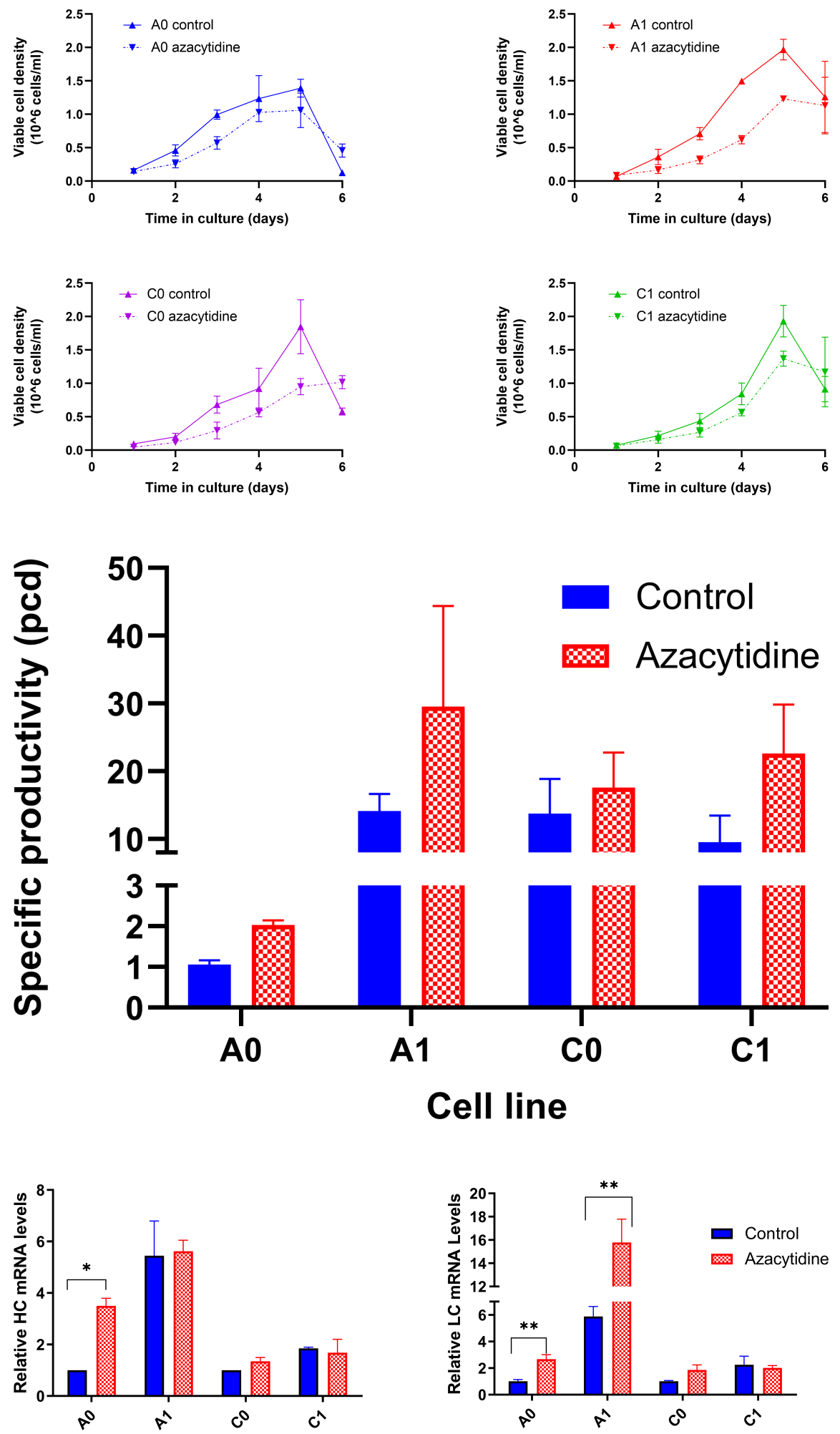


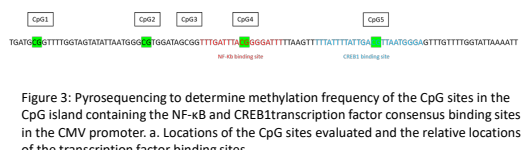

of the transcription factor binding sites. 

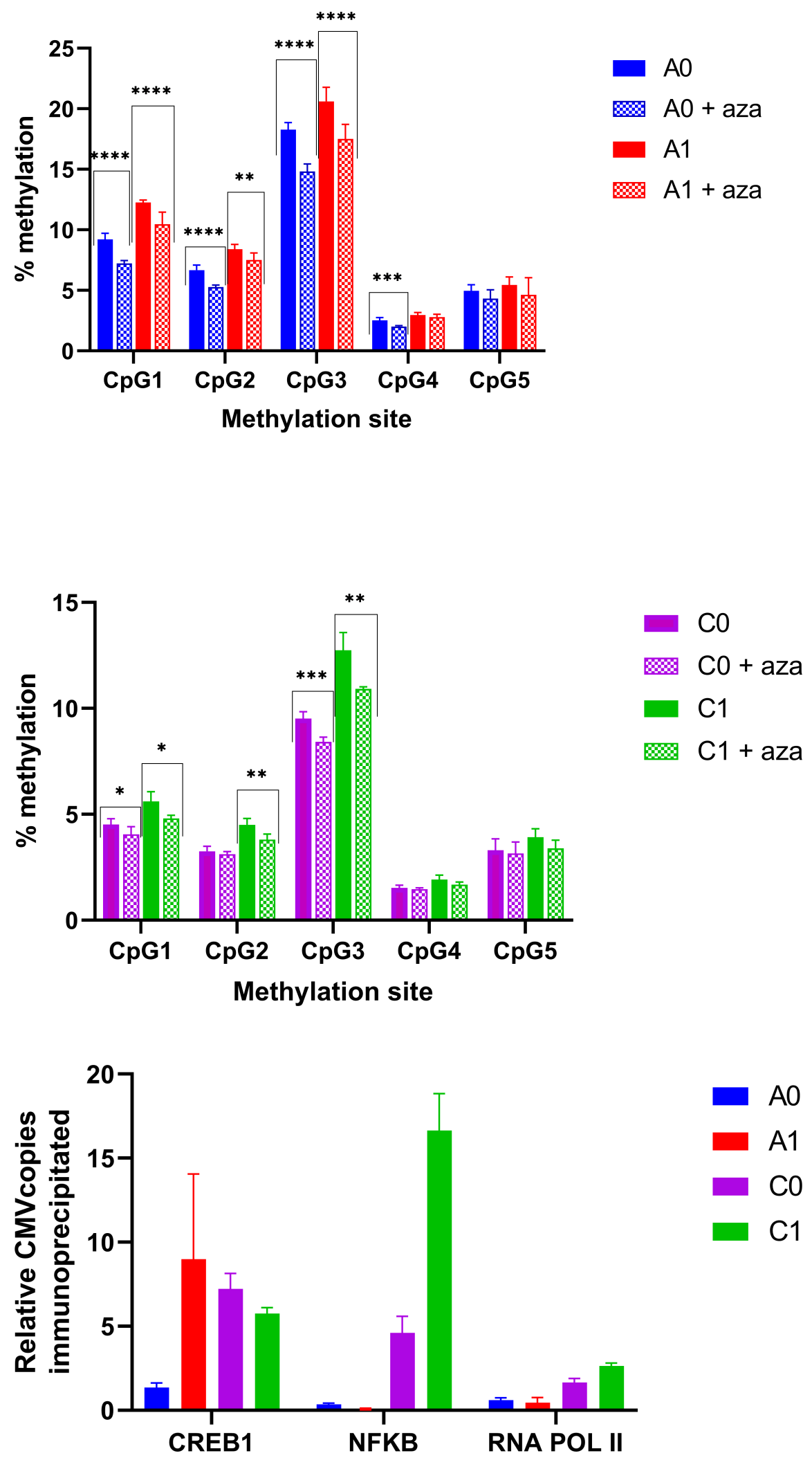